\title{
Evaluación de un curso en línea para la formación de competencias en el uso de las TIC en profesores de ciencias de secundarias públicas del sureste de México.
}

\section{Evaluation of an online course for skills training in the use of ICT in science teachers in public secondary Southeast Mexico}

\author{
J. Gabriel Domínguez Castillo \\ Universidad Autónoma de Yucatán. México. \\ jg.dominguez@correo.uady.mx \\ J. Samantha Morcillo Baquedano \\ Universidad Autónoma de Yucatán. México. \\ sam.morcillo@gmail.com
}

\begin{abstract}
Resumen
Este estudio surge como respuesta a la ausencia de información acerca de la evaluación de la efectividad de los cursos en línea en los cuales participan los profesores de educación básica en el sureste de México como parte de su entrenamiento en el uso de la tecnología ya que hoy en día, los docentes en ejercicio, necesitan ser competentes para ofrecer a sus estudiantes oportunidades de aprendizaje apoyadas en las TIC; para utilizarlas y para saber cómo estas pueden contribuir a su aprendizaje. La investigación es de tipo aplicada de corte mixto y participaron 30 profesores de ciencias y matemáticas pertenecientes a 19 escuelas secundarias de Mérida. En este trabajo se evaluó la efectividad del curso en línea y dentro de las categorías más importantes que emergieron se encontraron: Experiencia, las Expectativas, las Herramientas de trabajo y las Competencias relevantes. Los resultados se discuten bajo la Estrategia Digital Nacional (2013-2018) de México.
\end{abstract}

\section{Palabras clave}

Evaluación, TIC, Habilitación, Aprendizaje, Curso en línea.

\begin{abstract}
This study is a response to the lack of information on the evaluation of the effectiveness of online courses in which teachers of basic education in southeastern Mexico as part of their training in the use of technology involved since today day, practicing teachers need to be competent to offer students opportunities in ICT supported learning; to use them and know how they can contribute to their learning. The research is applied type of mixed cut and involved 30 science and math teachers from 19 secondary schools in Merida. In this paper the effectiveness of the online course was evaluated and in the most important categories that emerged were found: Experience, Expectations, Work tools and relevant skills. The results are discussed in the National Digital Strategy (2013-2018) of Mexico.
\end{abstract}

\section{Key words}

Evaluation, ICT, Empowerment, Learning, Online course

\section{Introducción}

El empleo de las TIC (Tecnologías de la Información y Comunicaciones), con el paso del tiempo, ha tomado una gran importancia en la formación escolar, siendo cada vez más recurrente y necesario la utilización de dichos recursos dentro de las aulas para 
incrementar la calidad educativa. A partir de dichos recursos se ha hecho posible una nueva forma de educación de carácter no presencial o a distancia, conocido como curso en línea.

En la literatura especializada un curso en línea se define como un proceso de enseñanzaaprendizaje de tipo interactivo fundamentado en la comunicación mediada por el ordenador en donde los estudiantes en vez de comunicarse de forma presencial, interactúan con el profesor, y los demás compañeros del curso, por medio del Internet a través del uso de charlas, debates, exámenes, pruebas cortas y otros dispositivos diferentes a los libros (Salmon, 2000; Ko y Rossen, 2001; Sandia, 2005).

Esta interacción enriquecedora de comunicación que propician los cursos en línea, forma parte de una modalidad de enseñanza denominada: educación a distancia. Los antecedentes de esta modalidad la ubican en la segunda mitad del siglo XIX, con las escuelas por correspondencia en Europa, las cuales tuvieron que enfrentar las críticas y el rechazo de las instituciones tradicionales de educación que desacreditaban sus procesos, restándoles credibilidad. Sin embargo, a pesar de estas, en la segunda mitad del siglo XX se desarrollaron proyectos impactantes en esta modalidad educativa, los cuales propiciaron un cambio de esta visión a nivel mundial.

En México la educación a distancia ha estado vinculada estrechamente con la educación abierta y sus orígenes comparten el impulso de los programas de educación pública organizados por el Estado (Bosco, 2008). De acuerdo con la identificación de algunos elementos de la educación a distancia ya como programa pedagógico con organización, estructura y metas de atención a problemas sociales, se presentó de forma evidente en el modelo implementado por la "Compañía Lancasteriana" creada en 1822 con el fin de promover la educación primaria entre los sectores marginados de la capital del país. Esta compañía retomó el sistema de enseñanza mutua que era practicado por algunos maestros particulares y por algunas escuelas gratuitas y conventos, donde un solo profesor podría enseñar a comunidades de 200 hasta 1000 alumnos, se basaba en dos principios: la extensión de los conocimientos más allá de la confrontación directa y el contacto físico entre el profesor y los estudiantes y la posibilidad de confrontar estructuras curriculares a cada individuo.

Posteriormente con la creación de la Secretaría de Educación Pública en 1921 se buscó la federalización de la educación, haciendo frente a la lucha contra el analfabetismo, impulsando la investigación científica y tecnológica y el desarrollo de las bellas artes. De ahí en 1966 se inicia de manera experimental la enseñanza secundaria por televisión (Telesecundaria) y en 1970 se gradúa la primera generación con 5437 personas. Este sistema utilizaba una pedagogía basada en el "mostrar" más que en el "explicar". Los implementos individuales consistían en un receptor de televisión (posteriormente se agregarían las videograbadoras), el maestro bajaba la programación diaria del curso y al terminar esta, organizaba discusiones con los estudiantes, aclaraba dudas y generaba actividades de aprendizaje. Todo lo anterior con el fin de atender las demandas en localidades donde no hubiera escuelas a través de la comunicación satelital. Al año siguiente en 1971, se realiza la propuesta para el establecimiento de la Universidad Abierta de la UNAM fundamentada en la reforma de la educación superior enfocada para atender aspectos más concretos de la realidad social del país.

Evaluación de un curso en línea para la formación de competencias en el uso de las TIC en profesores de ciencias de secundarias públicas del sureste de México. J. Gabriel Domínguez y J. Samantha Morcillo. 
De esta forma el proyecto de Sistema de Universidad Abierta (SUA) empezó a funcionar en 1972 procurando introducir a la Universidad y a los estudiantes en el sistema de producción y vincularlos más estrechamente a los trabajadores al ampliar sus formas de acceso a la educación universitaria con dos propósitos: a) dar alternativas de solución al problema de la masificación universitaria y, b) democratizar la enseñanza.

Atendiendo a la línea de la evolución de la educación en México, se vuelve necesario recordar que hasta hace algunos años, la gran mayoría de los profesores habían sido formados a través de la educación tradicional, desarrollada en ambientes tradicionales y con una pedagogía totalmente unidireccional, en los cuales la importancia de la educación radicaba en la concentración de la teoría, siendo esta transmitida del profesor al alumno (Schank, Berman y Macpherson, 2000) siendo distinguibles tres problemas: a) la enseñanza se centraba en el saber qué y no en el desarrollo de competencias, b) los conocimientos no ayudaban a los alumnos a lograr un objetivo que sea significativo y útil para ellos y c) los alumnos aprendían de manera descontextualizada. La revisión anterior permite tener un panorama de la evolución de la educación en México, desde la perspectiva de la educación tradicional, hasta los primeros registros de los sistemas de educación a distancia en nuestro contexto.

\section{Estudios recientes}

A continuación, se presentan algunos estudios realizados, donde se analiza la importancia que tienen los cursos de educación en línea en el robustecimiento de competencias en los estudiantes y algunos factores relevantes (motivación, confianza y atención) que influyen en el éxito de los mismos.

Algunos investigadores como Bebawi, (2005); Cantaluppi; (2005) y Cenich, (2005) sugieren que las instituciones $y$ organizaciones modernas requieren nuevas metodologías en la capacitación de sus empleados que impliquen el desarrollo de habilidades para la resolución de problemas, la toma de decisiones, la capacidad de trabajo colaborativo y la adaptación flexible a los cambios rápidos que se producen en las sociedades de información. Las razones anteriores proporcionan el marco de referencia por lo que la implementación de los cursos en línea para la educación moderna, es considerado un elemento viable en la formación de recursos humanos. Al mismo tiempo que la literatura especializada documenta que los cursos en línea mejoran la motivación (Alonso, 2010); mejora la confianza y las competencias de los estudiantes (Dominguez, Canto, Ortega y McCalman, 2016), cada vez son más los estudiantes que eligen estudiar en esta modalidad (Meyer, 2003) y de acuerdo con Long (2011) han demostrado ser más benéficos para estudiantes con alguna discapacidad, como la falta de audición.

Bryant y Bates (2015) por su parte, basándose en un ambiente constructivista en línea, remarcan la importancia de hacer un esfuerzo significativo para crear una conexión con los alumnos que no se muestran tan visibles en el curso, así como con los que participan con regularidad. Los investigadores indican que cada grupo requiere diferentes tipos de retroalimentación y atención y es importante el contacto con estos estudiantes para que ellos se sientan apoyados y no se sientan solos durante su progreso. De igual forma, señalan que una buena estrategia para el trabajo en ambientes virtuales es identificar momentos clave durante el periodo del curso, utilizar herramientas de comunicación para mantener el contacto con cada uno de los participantes, atender a tiempo sus dudas

Evaluación de un curso en línea para la formación de competencias en el uso de las TIC en profesores de ciencias de secundarias públicas del sureste de México. J. Gabriel Domínguez y J. Samantha Morcillo. 
y mantener el contacto permanente durante el desarrollo de las actividades de aprendizaje que se realicen.

De igual forma Karsenti (2010) y Domínguez (2015) demuestran cómo la motivación de los estudiantes dentro de un curso en línea aumenta significativamente durante el desarrollo de un ambiente tecnológicamente rico. Además, Karsenti indica que los cursos en línea influyen de manera positiva en la autodeterminación de los estudiantes, ya que ellos pueden elegir su lugar de trabajo e incluso trabajar a su propio ritmo, así como participar activamente en el desarrollo de su aprendizaje independiente. En estos ambientes, si los estudiantes desarrollan lazos de confianza desde el principio y se sienten acompañados fortalecerán su toma de decisiones, serán más conscientes del impacto de sus decisiones, será más sencillo el proceso de desarrollo de competencias y se creará un sentido de afiliación a través de los foros, correos, salas de chat y grupos de discusión electrónicos.

Shah, Goode, West y Clark (2014) indican que la educación a distancia o en línea, abre muchas oportunidades a grupos con un estado socioeconómico bajo, con residencias remotas a las universidades, mujeres mayores a los 25 años e individuos indígenas, cuyas oportunidades de acceso a la escuela no se encuentran con tanta facilidad. Por su parte Hernández, Romero y Ramírez (2014) mencionan que los cursos en línea requieren ser adecuados a las características de los usuarios para profundizar en estrategias metodológicas que propicien la interactividad y el trabajo colaborativo.

A nivel mundial la implementación de los cursos en línea como una modalidad educativa ha tenido un desarrollo exponencial (ver figura 1) tanto así que desde el año 2007 se da a conocer por David Wiley el primer curso masivo en línea (MOOC) que fue desarrollado en la Universidad Estatal de Utah. La popularidad de los MOOC ha aumentado tanto, que en el año 2012 fue considerado "el año de los MOOC" debido al indudable impacto y relevancia que han tenido en los procesos formativos actuales principalmente en la educación superior. Los tres principios básicos de este tipo de cursos son: gratuidad, masividad y la ubicuidad (Cormier y Siemens, 2010; Berman, 2012; Boxall, 2012).

Esta tendencia formativa es probablemente una de las innovaciones más destacadas en el área de educación y en el área de educación a distancia y su desarrollo aún es incipiente augurándole un gran impacto en los próximos años, debido a que en la actualidad los estudiantes universitarios están recurriendo a ellos como una opción de formación superior, como un complemento a su formación formal dado su carácter gratuito y ubicuo que cubre una vertiente que todavía hoy en día las universidades la tienen como uno de los retos o tareas pendientes (acceso a la educación y la extensión universitaria). Esta opción de formación en conjunto con las interfaces y ambientes personalizados que maneja, así como el uso de materiales amenos y de fácil acceso y descarga, propicia que los estudiantes consideren a los MOOC como una seria alternativa para llevar a cabo su formación. Incluso en la actualidad entre algunas de las instituciones más prestigiadas que emplean esta modalidad se incluyen Harvard, Berkeley, el MIT, University of London, Hong Kong Open University, Open University of China, Open Universities Australia y las plataformas más recurrentes para su implementación son: Coursera, Canvas Network, Edx, UniMooc, Khan Academy, Udacity y OpenClass. Por su parte Zapata-Ros (2013) destaca que los MOOC plantean

Evaluación de un curso en línea para la formación de competencias en el uso de las TIC en profesores de ciencias de secundarias públicas del sureste de México. J. Gabriel Domínguez y J. Samantha Morcillo. 
una realidad y son la respuesta a alguna de las características más destacables de la sociedad emergente.

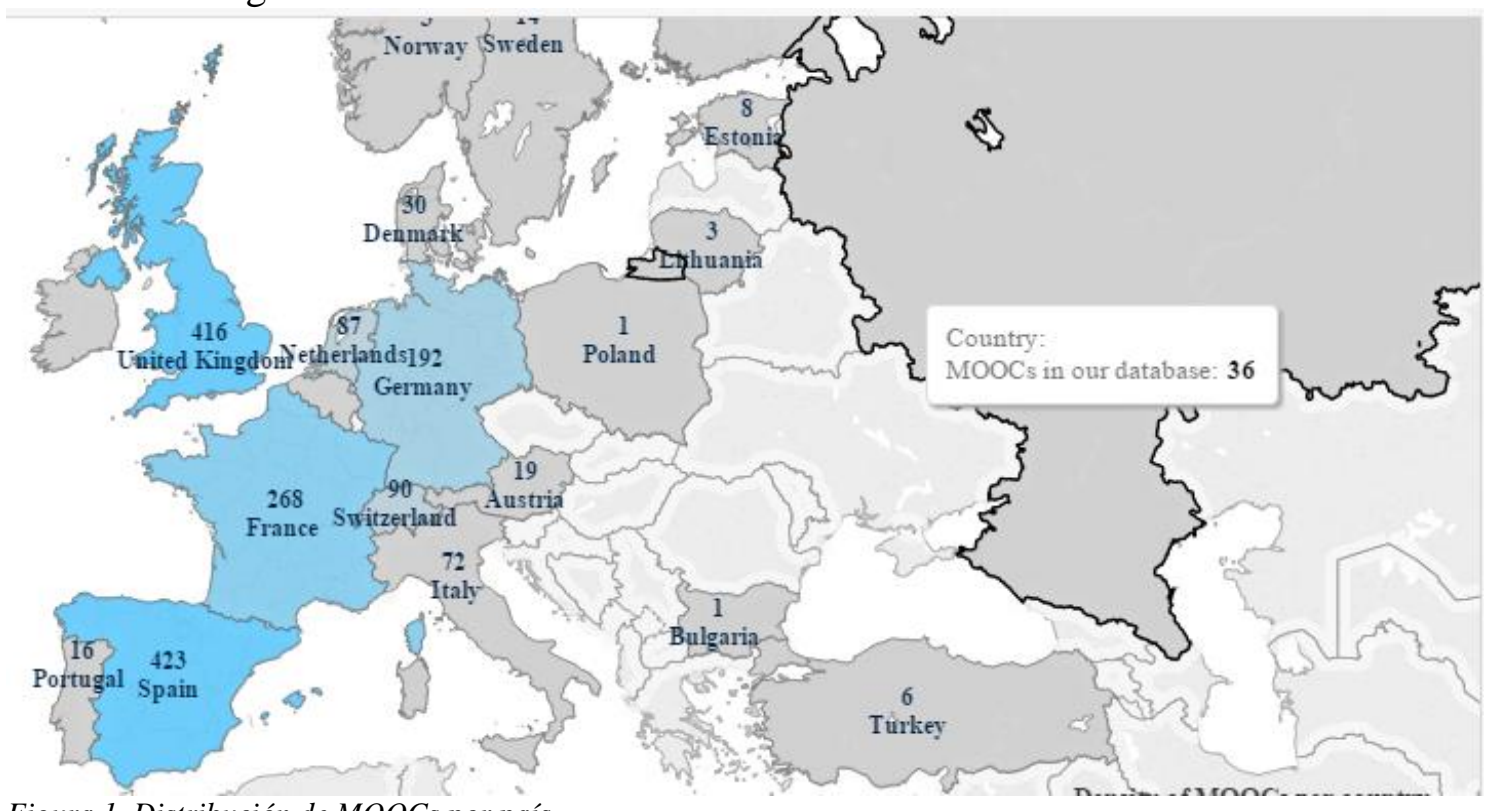

Figura 1. Distribución de MOOCs por país.

Tomado de: http://www.openeducationeuropa.eu/es/european_scoreboard_moocs

En el contexto mexicano, esta nueva forma de aprendizaje cada día toma más relevancia y presencia, un claro ejemplo es la formación de la CUAED (Coordinación de Universidad Abierta y Educación a Distancia), que es parte de la UNAM, la cual cuenta con una amplia variedad de cursos disponibles desarrollados en un ambiente virtual. Sin embargo, la metodología de evaluación de los cursos en línea es muy incipiente y no permite conocer y entender el modo y el grado en el que se han alcanzado las competencias de los estudiantes y el papel que juegan las distintas variables como el contexto, el acompañamiento, los conocimientos previos y los recursos utilizados.

Este artículo busca reforzar la cultura del proceso de evaluación de los cursos en línea, promoviendo un marco general del estado del arte de la literatura que pueda ser utilizado para el fortalecimiento de esta actividad. Nuestra justificación radica en que, al tener un instrumento que cuantifique y cualifique los cursos en línea, a través de una metodología aplicada, se podrán establecer las bases necesarias para la calidad en esta modalidad en nuestro contexto, logrando así un estándar del cual deberá cumplir cada curso, ya que desde la óptica de la literatura especializada un buen curso en línea debe cumplir con rigurosos estándares de calidad, que mejoren el aprendizaje de los estudiantes (International North American Council for Online Learning, 2011; Quesada, 2006; Universidad Virtual de Michigan, 2002). Cuando esto ocurra, más universidades se verán interesadas en la creación de cursos en esta modalidad, con el fin de ir evolucionando en la forma de crear aprendizaje y mejorar las competencias de sus estudiantes y su inserción laboral.

Sin embargo, a pesar de los avances en esta área, el personal docente hasta el día de hoy, ve de una manera menos positiva los cursos en línea a diferencia de los estudiantes (Heaton-Shrestha, 2009). Un estudio realizado por Díaz y Entonado (2009) demostró que los maestros se relacionan más con sus estudiantes cuando trabajan en un curso en línea que con sus estudiantes en el método tradicional, de hecho, algunos maestros

Evaluación de un curso en línea para la formación de competencias en el uso de las TIC en profesores de ciencias de secundarias públicas del sureste de México. J. Gabriel Domínguez y J. Samantha Morcillo. 
llegan a conocer mejor a sus estudiantes gracias a la apertura y la interacción que se da en estos ambientes no convencionales.

Montilva, Barrios y Sandia (2002) propusieron un método de evaluación compuesto por tres elementos, los cuales son: un modelo conceptual de cursos en línea, un proceso de evaluación y un modelo de organización de un grupo de evaluación. (Ver Figura 2)

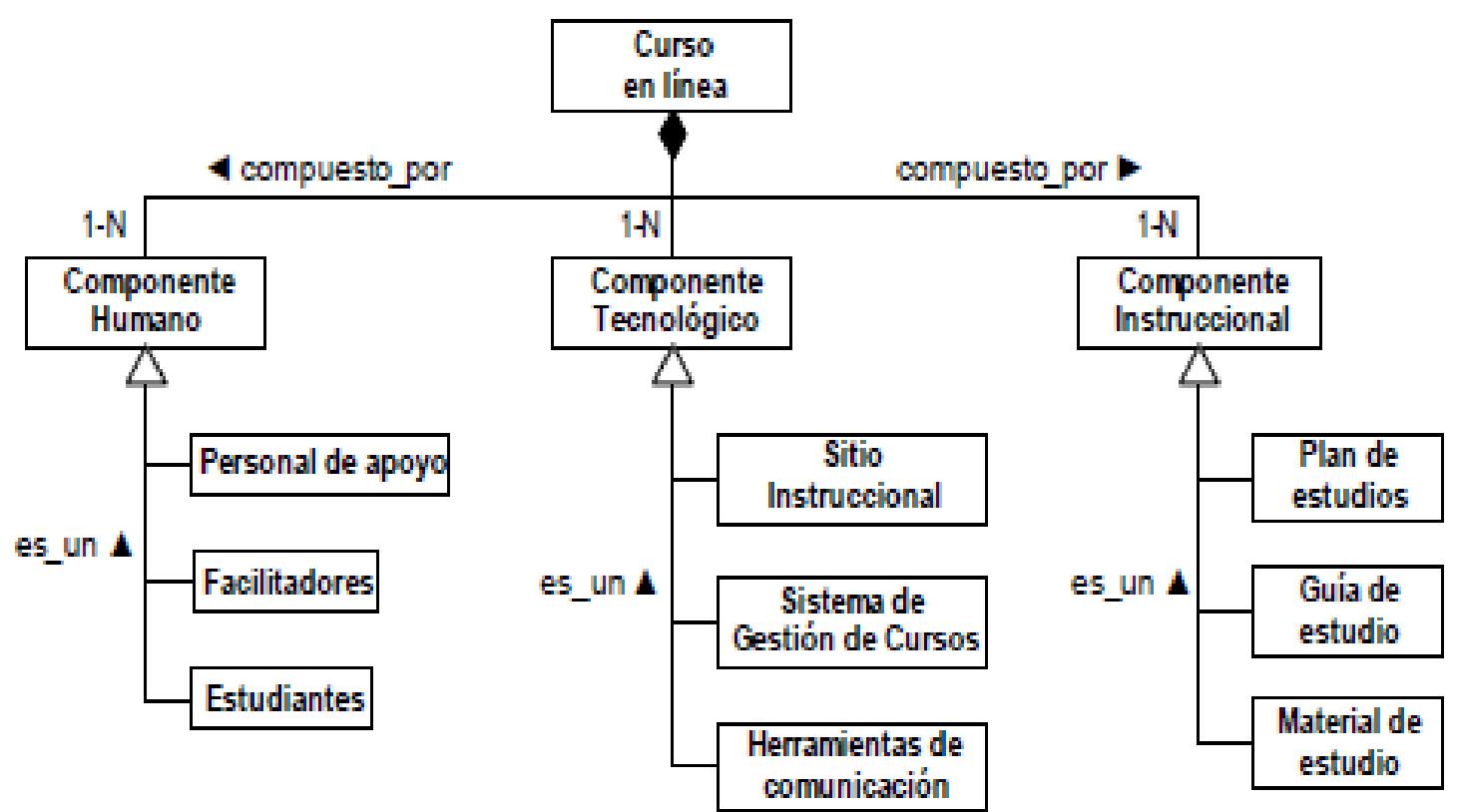

Figura 2. Elementos esenciales de un curso en línea. Tomado de Montilva, Barrios y Sandia (2002).

De acuerdo con los autores el componente humano está compuesto por facilitadores, estudiantes y personal que provee apoyo para la elaboración de los componentes instruccionales como los administradores de los sitios o los diseñadores de los mismos.

El componente instruccional está integrado por el plan de estudios, el material instruccional y la guía de estudios, esta última en particular incluye los contenidos del curso y describe cada una de las actividades de aprendizaje que los estudiantes deben llevar a cabo.

Mientras que el componente tecnológico consta del sitio instruccional, que es el medio virtual utilizado para comunicarse entre sí y con los componentes instruccionales, las herramientas de comunicación están integradas en el ya mencionado sitio, que necesita un sistema de gestión de cursos, siendo este el software que permite a los humanos el desarrollo, uso y mantenimiento del sitio.

Sandia, Montilva y Barrios (2005) describen seis fases para el proceso de evaluación de los cursos en línea:

- Fase 1. Análisis del curso en línea.

- Fase 2. Definición de los requisitos de la evaluación.

- Fase 3. Diseño del instrumento de medida.

- Fase 4. Producción del instrumento de medida.

- Fase 5. Administración de las pruebas.

$\overline{\text { Evaluación de un curso en línea para la formación de competencias en el uso de las TIC en profesores de }}$ ciencias de secundarias públicas del sureste de México. J. Gabriel Domínguez y J. Samantha Morcillo. 
- Fase 6. Análisis de los datos.

Por otra parte Khan (2005) propone seis dimensiones de estudio, las cuales son: pedagógica, tecnológica, diseño de interfaz, evaluación, gestión y apoyo.

Mayorga y Madrid (2011) mencionan que los indicadores principales para un curso en línea con tutor son:

- Indicador 1: Acceso a la información del curso

- Indicador 2: Matriculación

- Indicador 3: Alta y acceso a la plataforma

- Indicador 4: Familiarización con la plataforma

- Indicador 5: Descarga y obtención de materiales

- Indicador 6: Control de fechas límite de envío de ejercicios

- Indicador 7: Realización de trabajos en cada unidad o módulo

- Indicador 8: Foros y actividades de grupo

- Indicador 9. Realización de actividades complementarias

- Indicador 10: Realización de tests de las unidades o módulos

- Indicador 11: Realización de test final

- Indicador 12: Acreditación

- Indicador 13: Sistema tutorial

Otros investigadores como Colás, Rodríguez y Jiménez (2002) analizaron algunos indicadores que se podían utilizar para evaluar al e-learning desde una perspectiva sociocultural. Planteando como principales indicadores de evaluación de los aprendizajes mediados por un ordenador los siguientes: Dominio, Privilegiación, Reintegración, Apropiación, Control de la actividad, Formas de Interactividad. Representación de la meta y Responsabilidad en la tarea.

\section{Método}

El desarrollo metodológico de esta investigación fue de tipo aplicada y de corte mixto. El diseño se llevó a cabo bajo el enfoque de la metodología de la investigación acción, que constituye un método de investigación científica muy utilizado en la actualidad y ocupa un lugar relevante en diversos países (Gran Bretaña, Alemania, EEUU, España, Canadá y Australia) (Elliot, 2005; Boggino, Rosekrans, 2007; Susman, 1983). De acuerdo con Elliot (2005) la formación del profesorado se ha ido centrando cada vez más en los problemas prácticos que tanto las escuelas como los profesores tienen que afrontar en su trabajo y la tendencia observada se complementa con la preocupación de auxiliar a los profesores para que puedan reflexionar más profundamente acerca de su práctica educativa en las escuelas.

En este estudio como parte de la metodología utilizada (Elliot, 2005; Kemmis, 1988), la etapa de la acción se evidenció a través de la implementación de un curso virtual que estuvo constituido por trece unidades, que se construyeron y se presentaron en un orden gradual de complejidad. El programa inició considerando los conocimientos básicos de cómputo de los profesores, hasta el uso de las herramientas de la web 2.0, enfatizando que, durante el desarrollo del curso los profesores podían realizar sugerencias y recomendaciones con respecto a contenidos relevantes de su práctica docente que quisieran ser abordados, cuidando los aspectos de la metodología que recomienda que los participantes examinen su propia práctica educativa sistemáticamente y cuidadosamente.

Evaluación de un curso en línea para la formación de competencias en el uso de las TIC en profesores de ciencias de secundarias públicas del sureste de México. J. Gabriel Domínguez y J. Samantha Morcillo. 
En la muestra de participaron estuvo integrada por 30 profesores de ciencias y matemáticas pertenecientes a 19 escuelas secundarias de Mérida. La técnica de recolección de datos cuantitativos se realizó por medio de una encuesta orientada a conocer la opinión de los profesores con respecto a los tres dominios (entorno y metodología didáctica, navegación y diseño y recursos multimedia) que integran el curso y se complementa con el análisis de datos cualitativos provenientes de entrevistas personales y grupos focales que buscaron profundizar en la interpretación de los resultados obtenidos acerca de la evaluación del curso.

El proceso de análisis de los datos cualitativos involucró cuatro etapas: la preparación de los datos (recogida y el almacenamiento de los datos); el análisis inicial (codificación abierta); el análisis principal (refinamiento del sistema indexado) y los resultados (conceptos clave, relaciones y modelos) que integraron los hallazgos principales que se describen en este estudio.

De esta manera la investigación tiene como propósito: contribuir al conocimiento acerca de la evaluación de los cursos en línea para promover la formación de competencias en el uso de las Tic. Esta información permitirá la toma de decisiones respecto a la implementación de programas de habilitación para mejorar las prácticas existentes a nivel local, promoviendo el fortalecimiento de los cursos en línea, basado en altos estándares de calidad.

\section{Participantes}

En el municipio de Mérida y sus zonas circunvecinas, existen 17 escuelas secundarias $(46 \%)$ pertenecientes al sistema federal y 20 escuelas secundarias $(54 \%)$ pertenecientes al nivel estatal. De las 37 escuelas secundarias que existen en el municipio y sus alrededores se trabajó con 9 escuelas secundarias federales y 10 escuelas secundarias estatales que en conjunto integran a 19 escuelas que voluntariamente accedieron a participar en el estudio (ver Tabla 1).

Tabla 1 Características de las escuelas y profesores participantes

\begin{tabular}{cccccc}
\hline $\mathbf{N}^{\circ}$ & Escuela & $\begin{array}{c}\text { Sistema al que } \\
\text { pertenece }\end{array}$ & Zona de la escuela & $\begin{array}{c}\text { Población } \\
\text { teórica }\end{array}$ & $\begin{array}{c}\text { Población } \\
\text { Accesible }\end{array}$ \\
\hline 1. & SBB & Federales & Matutino/Vespertino & 6 & 1 \\
2. & JV & Federales & Matutino/Vespertino & 3 & 1 \\
3. & REBP & Federales & Matutino & 2 & 1 \\
4. & EVR & Federales & Matutino/Vespertino & 5 & 2 \\
5. & ABV & Federales & Matutino/Vespertino & 4 & 0 \\
6. & JEVG & Federales & Matutino/Vespertino & 4 & 3 \\
7. & EAG & Federales & Matutino/Vespertino & 5 & 3 \\
8. & JRH & Federales & Matutino/Vespertino & 4 & 1 \\
9. & TEC13 & Federales & Matutino/Vespertino & 1 & 1 \\
10. & GNB & Estatales & Matutino/Vespertino & 4 & 3 \\
11. & SR & Estatales & Matutino & 6 & 4 \\
12. & AVC & Estatales & Matutino/Vespertino & 3 & 2 \\
13. & GSA & Estatales & Matutino & 4 & 2 \\
14. & LAB & Estatales & Matutino/Vespertino & 4 & 0 \\
15. & RM & Estatales & Matutino & 3 & 0 \\
16. & CCA & Estatales & Matutino & 3 & 1 \\
17. & BJG & Estatales & Matutina & 2 & 2 \\
\hline
\end{tabular}

$\overline{\text { Evaluación de un curso en línea para la formación de competencias en el uso de las TIC en profesores de }}$ ciencias de secundarias públicas del sureste de México. J. Gabriel Domínguez y J. Samantha Morcillo. 


\begin{tabular}{cccccc}
\hline 18. & HLyL & Estatales & Vespertino & 4 & 2 \\
19. & ACC & Estatales & Matutino & 3 & 1 \\
\hline & Total & & & 70 & 30 \\
\hline
\end{tabular}

La población teórica, estuvo constituida por el conjunto de profesores a los cuales se quiere extrapolar los resultados. Particularmente para este estudio, la población estuvo conformada por profesores que como parte de su ejercicio docente imparten alguna asignatura relacionada con el área de las ciencias (Matemáticas, Física, Química y Biología) y que participaron en la administración del estudio diagnóstico que se realizó en las 19 escuelas secundarias del municipio de Mérida y algunas de sus zonas rurales circunvecinas (Uman, Caucel, Acanceh).

\section{Instrumento}

En este estudio se elaboró un instrumento denominado: Evaluación del curso virtual DICUTICDS, que estuvo integrado por cuatro secciones, dos de datos generales relevantes para el estudio (sujeto e institución), una sección dedicada a la evaluación de las características del curso virtual que involucró tres dominios: Entorno y metodología didáctica, Navegación y Diseño y Recursos Multimedia y una sección de sugerencias para la mejora del curso. Este instrumento integró una escala valorativa tipo Likert de recolección de datos primarios de un solo paso y cinco niveles que denotan la frecuencia con que se presentaron las características incluidas en el instrumento (ver Figura 3).

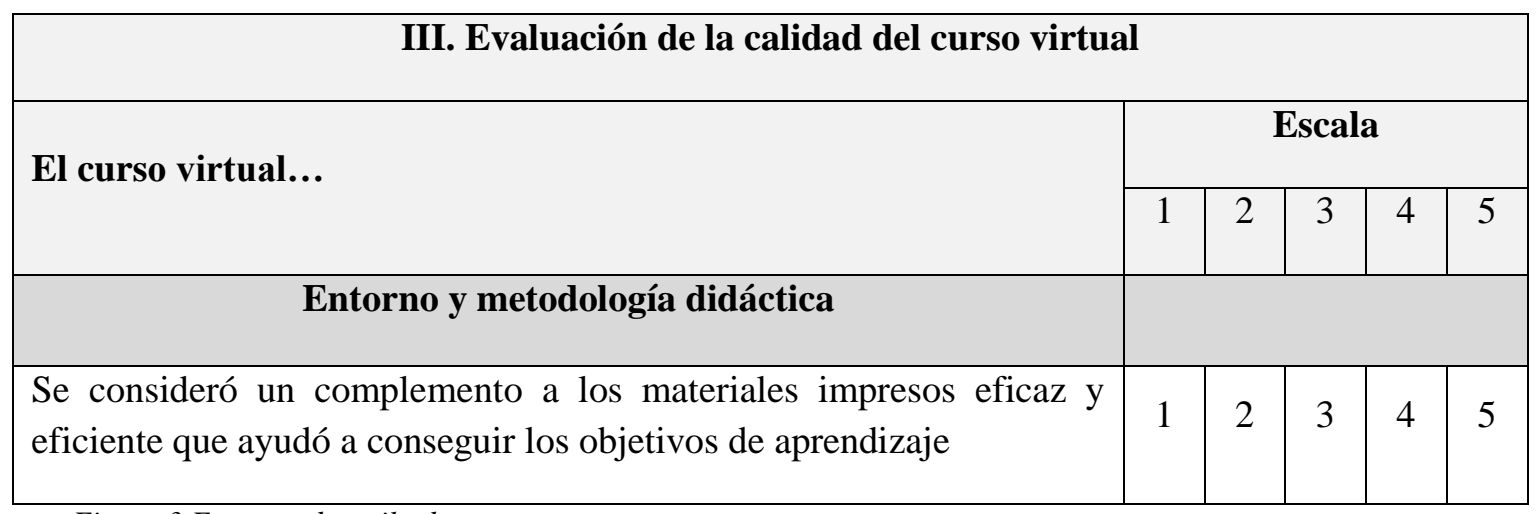

Figura 3 Formato de estilo de respuesta

Como parte de la metodología se utilizó el coeficiente alpha, para conocer la consistencia interna de los reactivos que constituyeron el instrumento, para lo cual se obtuvo el indicador global $(\alpha=.923)$ y el de cada uno de los dominios de manera separada. Los resultados se ilustran en la Tabla 2.

Tabla 2 Confiabilidad de los dominios

\begin{tabular}{ccc}
\hline $\mathbf{N}^{\circ}$ & Dominio & $\boldsymbol{\alpha}$ \\
\hline I & Entorno y metodología didáctica & .833 \\
II & Navegación y diseño & .852 \\
III & Recursos multimedia & .761
\end{tabular}

$\overline{\text { Evaluación de un curso en línea para la formación de competencias en el uso de las TIC en profesores de }}$ ciencias de secundarias públicas del sureste de México. J. Gabriel Domínguez y J. Samantha Morcillo. 
El primer dominio (entorno y metodología didáctica) englobó los requerimientos que son imprescindibles para que el estudiante se sintiera a gusto con la interfase utilizada y con los procesos para la adquisición del aprendizaje. La tabla muestra que este dominio obtuvo un alfa adecuado $(\propto=.833)$ que fortaleció al instrumento. Posteriormente el segundo dominio (navegación y diseño) involucró todo lo relacionado a las formas y procedimientos para conducirse en el curso, como puede verse los resultados indican que el indicador para este dominio fue el más alto $(\alpha=.852)$. El último dominio (recursos multimedia) se enfocó al desarrollo de materiales que se utilizaron en el curso y como puede observarse el alfa que se registró fue el más bajo $(\alpha=.761)$, pero dentro del rango aceptable.

\section{Resultados}

En esta sección se presentan los principales hallazgos relacionados con la evaluación del curso virtual en el cual participaron los profesores de ciencias de secundaria. La Tabla 3 , presenta el análisis del dominio entorno y metodología didáctica y los resultados presentan características importantes de resaltar. Primero, como puede observarse la mayoría de los profesores evaluó con una calificación superior a 4 (casi siempre) cada uno de los indicadores, siendo el valor más bajo $(\underline{x}=4.44)$ y el valor más alto $(\underline{x}=$ 4.96). Este comportamiento permite inferir que la mayoría de los indicadores que se incluyeron en esta categoría se realizaron con una alta frecuencia, denotando un buen nivel en el desarrollo de este dominio. Segundo, el dominio de entorno y metodología didáctica desde el punto de vista de los autores constituyó un complemento didáctico imprescindible para el estudio y un apoyo en el proceso de enseñanza de los participantes del curso en línea. Los resultados muestran que este dominio obtuvo un promedio general de $\underline{x}=4.75$, lo que desde el punto de vista de la escala utilizada se considera que se logró en un buen nivel de desarrollo.

Tabla 3 Entorno y metodología didáctica

\begin{tabular}{lccc}
\hline \multicolumn{1}{c}{ Subdominios } & $\underline{\boldsymbol{x}}$ & $\check{\boldsymbol{x}}$ & $\boldsymbol{\sigma}$ \\
\hline Complemento para conseguir objetivos de aprendizaje & 4.44 & 5 & 1.12 \\
Incluyó mecanismos de supervisión a través de la red & 4.63 & 5 & .647 \\
Compensó la inversión de mi tiempo & 4.76 & 5 & .436 \\
Entorno amigable y adaptable & 4.96 & 5 & .200 \\
Potenció el pensamiento divergente y la discusión & 4.58 & 5 & .504 \\
Fue agradable y transmitió una impresión de credibilidad & 4.80 & 5 & .408 \\
Facilitó la relación entre el usuario y la computadora & 4.76 & 5 & .523 \\
Propició la participación individual y en grupo & 4.88 & 5 & .338 \\
Incluyó el desarrollo de contenidos exhaustivos & 4.80 & 5 & .500 \\
Presentó exactitud y claridad en los contenidos & 4.60 & 5 & .500 \\
Atendió a distintos estilos de aprendizaje & 4.56 & 5 & .583 \\
Facilitó la información a través de la metodología didáctica & 4.92 & 5 & .277 \\
Incluyó actividades variadas que facilitaron la comprensión & 4.80 & 5 & .500 \\
Incluyó herramientas de evaluación de calidad didáctica & 4.84 & 5 & .374 \\
Potenció el desarrollo de actitudes positivas hacia el estudio & 4.84 & 5 & .374 \\
\hline
\end{tabular}

$\overline{\text { Evaluación de un curso en línea para la formación de competencias en el uso de las TIC en profesores de }}$ ciencias de secundarias públicas del sureste de México. J. Gabriel Domínguez y J. Samantha Morcillo. 
En la Tabla 4 se presenta el análisis del dominio navegación y diseño. Como puede observarse, los 10 indicadores se comportan de manera similar a la Tabla 3 presentando valores superiores a 4 (casi siempre). Este comportamiento es indicativo de una valoración superior en este dominio. A continuación, se presenta la estadística descriptiva para este dominio y se observan características importantes de resaltar. Primero, como se muestra a continuación, los profesores otorgaron una valoración superior a 4 (casi siempre) en todos los indicadores del dominio, siendo el valor más bajo $(\underline{x}=4.84)$ y el valor más alto $(\underline{x}=4.96)$. Debido al comportamiento de los resultados obtenidos se puede concluir que los indicadores de este dominio en su totalidad mostraron una alta frecuencia, alcanzando de esta manera un buen nivel en el desarrollo de este dominio.

Tabla 4 Navegación y Diseño

\begin{tabular}{lccc}
\multicolumn{1}{c}{ Tabla 4 Navegación y Diseño } & $\underline{\boldsymbol{x}}$ & $\breve{\boldsymbol{x}}$ & $\boldsymbol{\sigma}$ \\
\hline Presentó una organización adecuada & 4.92 & 5 & .277 \\
Incluyó distintas opciones de navegación & 4.84 & 5 & .624 \\
Facilitó la localización de los recursos multimedia & 4.84 & 5 & .374 \\
Presentó encabezados, títulos y avisos detallados & 4.92 & 5 & .277 \\
Incluyó el diseño de vínculos adecuados & 4.88 & 5 & .332 \\
El diseño de los iconos y botones fue adecuado & 4.80 & 5 & .500 \\
Presentó herramientas con calidad técnica & 4.80 & 5 & .408 \\
Incorporó tableros de anuncios que facilitaron búsquedas & 4.88 & 5 & .332 \\
Incluyó guías de trabajo & 4.88 & 5 & .332 \\
Cuidó la consistencia de las rutas de entrega de tareas & 4.96 & 5 & .200 \\
\hline
\end{tabular}

Segundo, el dominio de navegación y diseño desde el punto de vista de los autores constituyó un proceso sistemático, planificado y estructurado que permitió el fortalecimiento de las competencias en favor de su aprendizaje mediante la implementación de un curso funcional y de fácil acceso para los estudiantes, más allá de los contenidos planos.

Tercero, los resultados señalan que este dominio presentó un promedio general de $\underline{x}=$ 4.87, lo que desde el punto de vista de la escala utilizada se considera que se logró en un buen nivel de desarrollo.

Cuarto, los resultados de este apartado ponen de manifiesto, la importancia que tiene la navegación y el diseño en la confección de los cursos en línea, ya que de acuerdo con varios estudios (Romero, Ventura y Hervás, 2005) existe muy poca evidencia científica pertinente acerca de la navegación de los estudiantes en ambientes informáticos de aprendizaje.

La Tabla 5 expone el análisis del dominio recursos multimedia y de acuerdo con los datos obtenidos se logran identificar características importantes. Primero, como se observa, los profesores evaluaron con calificaciones superiores a 4 (casi siempre) todos

$\overline{\text { Evaluación de un curso en línea para la formación de competencias en el uso de las TIC en profesores de }}$ ciencias de secundarias públicas del sureste de México. J. Gabriel Domínguez y J. Samantha Morcillo. 
los indicadores, las puntuaciones más bajas se registraron en el indicador "Los recursos eran descargables e imprimibles" ( $\underline{x}=4.46)$ y las puntuaciones más altas en el indicador "La información multimedia incluyó las referencias" $(\underline{x}=4.88)$. Segundo, el dominio de navegación y diseño desde el punto de vista de los autores constituyó un elemento imprescindible para la generación de conocimiento dado que permitió atraer, ampliar y ejemplificar los tópicos presentados durante la realización del curso virtual. Tercero, por medio de estos resultados, se obtuvo un promedio general de $\underline{x}=4.73$, lo que desde el punto de vista de la escala utilizada se considera que se logró en un buen nivel de desarrollo.

Tabla 5 Recursos Multimedia

\begin{tabular}{lccc}
\multicolumn{1}{c}{ Tabla 5 Recursos Multimedia } & $\underline{\boldsymbol{x}}$ & $\underline{\boldsymbol{x}}$ & $\boldsymbol{\sigma}$ \\
\hline Incluyó distintos recursos multimedia & 4.83 & 5 & .381 \\
La información multimedia incluyó las referencias & 4.88 & 5 & .338 \\
Los recursos fueron adaptados a las competencias & 4.75 & 5 & .442 \\
Las imágenes fueron legibles y adecuadas & 4.79 & 5 & .415 \\
Los recursos eran descargables e imprimibles & 4.46 & 5 & .833 \\
Incluyó e-books & 4.71 & 5 & .550 \\
Incluyó herramientas de la web 2.0 & 4.83 & 5 & .381 \\
Incluyó manuales de uso de los recursos & 4.63 & 5 & .647 \\
\hline
\end{tabular}

La Figura 4 presenta los comportamientos de las barras de error generadas a partir de los grupos de edad de los participantes y cruzadas con los dominios analizados. Los grupos de edad estuvieron clasificados de la siguiente manera: grupo 1 (22 a 31), grupo 2 (32 a 41 años), grupo 3 (42 a 51 años) y grupo 4 (52 a 61 años). Los dominios evaluados se presentaron en el siguiente orden: Entorno y metodología didáctica (EMD); Navegación y diseño (ND) y Recursos multimedia (RM).

Los resultados observados en la figura, dan cuenta del comportamiento de los cuatro dominios y presentan características importantes de resaltar.

Primero, los puntajes más altos por grupo de edad, correspondieron a EMD y ND en cada uno de los grupos de edad (32 a 41 años; 42 a 51 años y 52 a 61 años) a excepción del primer grupo de edad de 22 a 31 años.

Segundo, como puede observarse en las gráficas las barras de error fueron más consistentes en el cuarto grupo de edad que aglutino al $44 \%$ de la población, seguido del tercer grupo de edad que aglutinó a un 32\%. Como puede observarse la gráfica indica que más del $70 \%$ de la población de profesores que participaron en el curso son mayores de 40 años y la mayoría de ellos posee una antigüedad promedio de 20 años.

Tercero, como se observa, los intervalos de confianza fueron más amplios para el tercer grupo de edad (42 a 51 años) y los valores medios para los grupos centrales fueron similares, lo que denota un comportamiento similar en las poblaciones de los dos grupos con respecto a la evaluación del curso en línea en el que participaron.

Cuarto, el dominio que registró mayor puntaje en todos los grupos de edad, fue el de navegación y diseño (ND) este comportamiento pone de manifiesto la importancia que

Evaluación de un curso en línea para la formación de competencias en el uso de las TIC en profesores de ciencias de secundarias públicas del sureste de México. J. Gabriel Domínguez y J. Samantha Morcillo. 
le dieron los participantes al establecimiento de lineamiento precisos en cuanto a la elección pertinente de los materiales durante el proceso formativo, a la accesibilidad de los recursos y a la asesoría sistemática del tutor durante el desarrollo del programa.

Edad Agrupada

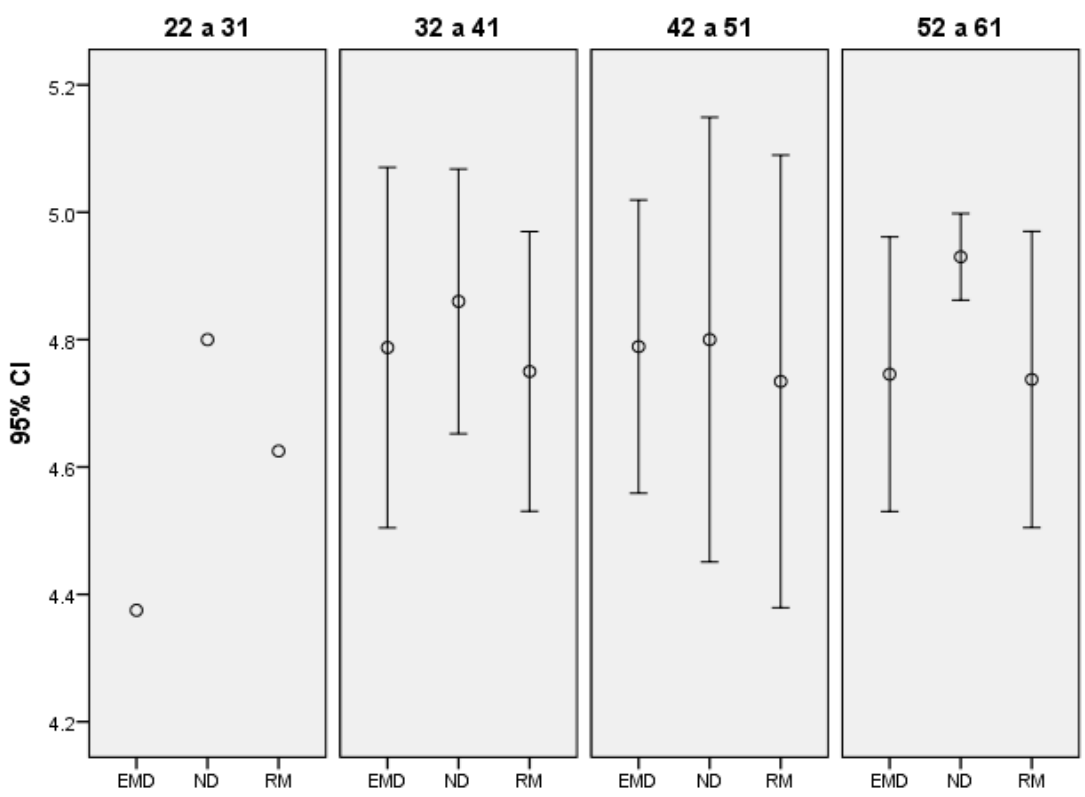

Figura 4 Barras de error para la variable edad

Como parte de la metodología utilizada se realizaron 24 entrevistas personales a los profesores que concluyeron el programa y dos grupos focales. El primer grupo focal lo conformaron 11 profesores, constituidos por 7 mujeres y 4 hombres. El segundo, lo conformaron 7 profesores, constituido por 5 mujeres y 2 hombres. Las entrevistas realizadas en los dos grupos focales fueron grabadas solamente en audio (archivo .mp3) y luego transcritas en un documento de Word.

Para el análisis e interpretación de los datos cualitativos se utilizó el programa ATLAS.ti (versión 8) que es un potente conjunto de herramientas para el análisis cualitativo de grandes cuerpos de datos textuales y gráficos a partir de la creación de una unidad hermenéutica (UH). El proceso de análisis de los datos involucró cuatro etapas: la preparación de los datos (recogida y el almacenamiento de los datos), el análisis inicial (codificación abierta), el análisis principal (refinamiento del sistema indexado) y los resultados (conceptos clave, relaciones y modelos).

Así, a partir del procedimiento de Codificación Abierta emergieron categorías y subcategorías que están representadas por redes conceptuales que sirven de recurso gráfico para las interpretaciones de los resultados obtenidos. Como resultado del análisis e interpretación de los datos se construyó una red conceptual denominada: Evaluación de DICUTICDs (ver Figura 5) que incluyó 4 principales categorías (experiencias con el curso en línea, expectativas del curso, herramientas de trabajo y competencias relevantes) que emergieron con el procedimiento de Codificación Abierta. En dicha figura se presenta de manera esquemática, un modelo de interpretación de los datos acerca de los elementos que en opinión de los interlocutores fueron los más relevantes en la evaluación del programa formativo.

Evaluación de un curso en línea para la formación de competencias en el uso de las TIC en profesores de ciencias de secundarias públicas del sureste de México. J. Gabriel Domínguez y J. Samantha Morcillo. 


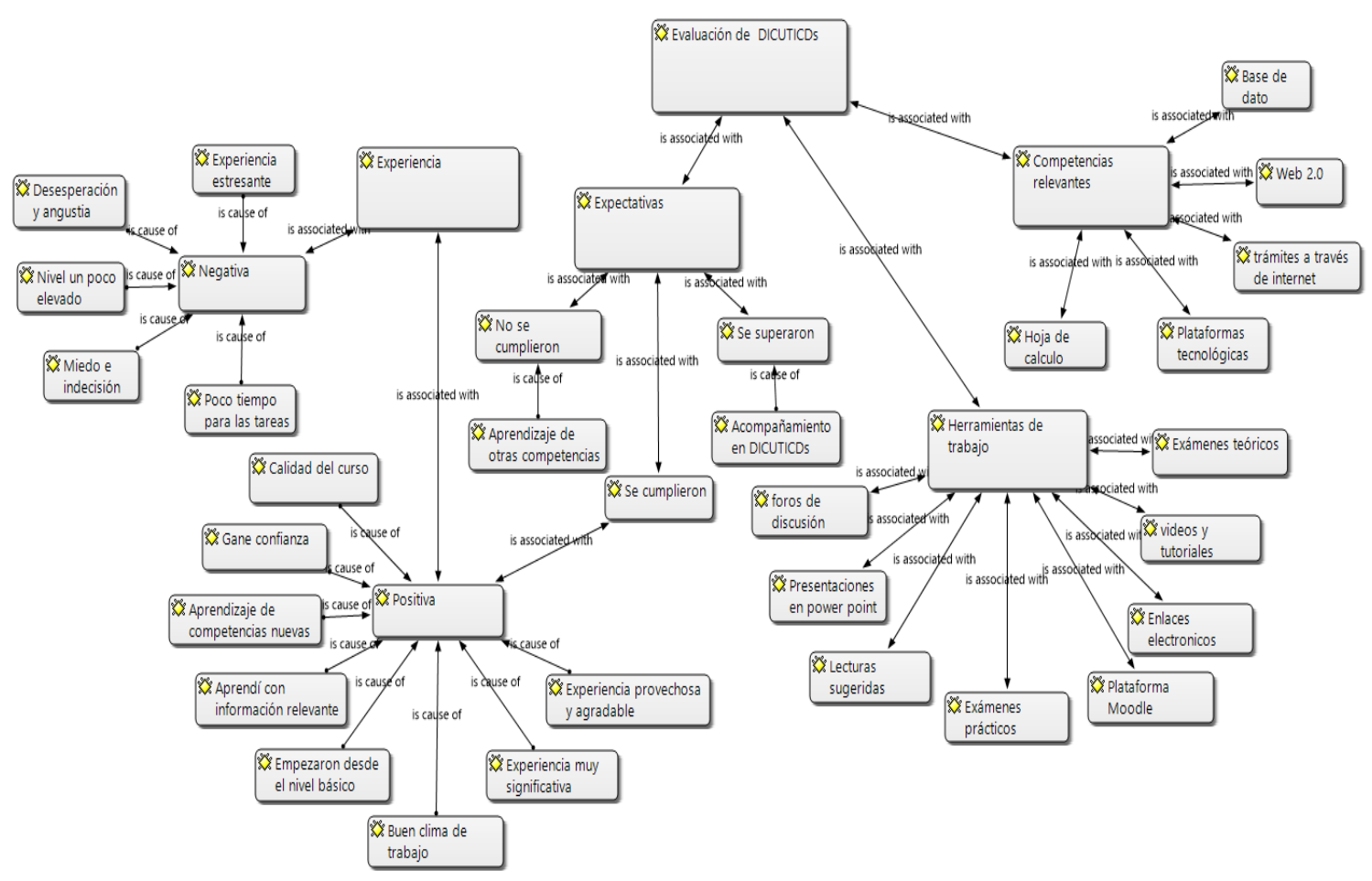

Figura 5 Evaluación del curso virtual

Como se puede observar en la figura anterior, se establecen como principales categorías: la Experiencia (opinión de los interlocutores con respecto al programa), las Expectativas (analizando si lo esperado se cumplió), las Herramientas de trabajo (la variedad de recursos que tuvieron disponibles), las Competencias relevantes (las que en opinión de los interlocutores fueron las más significativas).

A continuación, y para un mejor entendimiento se presentan las principales categorías con sus respectivas subcategorías. En la figura 6 se presenta la categoría experiencia, con sus respectivas subcategorías que la integraron extraídas con el procedimiento de codificación abierta.

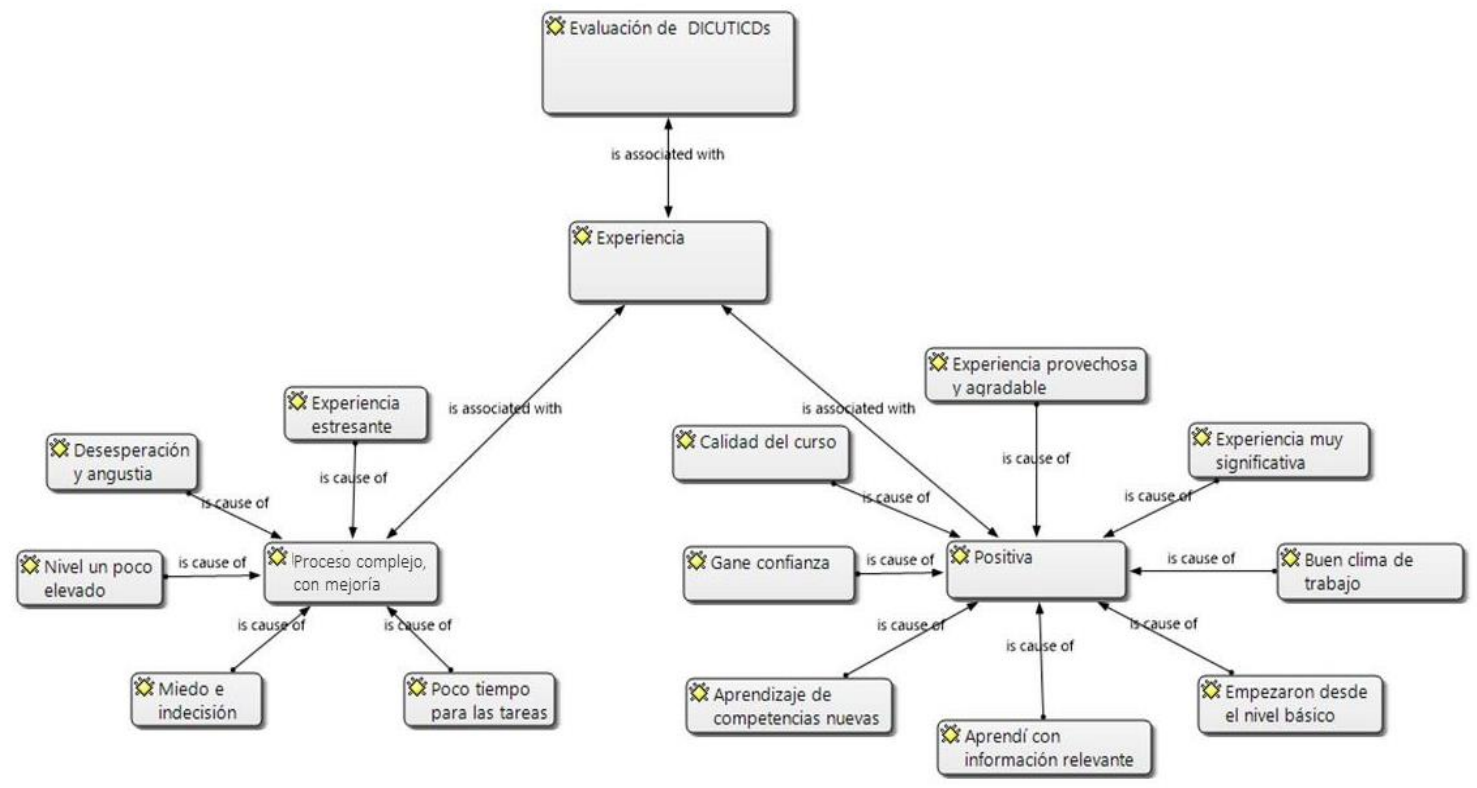

Figura 6. Red conceptual de la experiencia del curso en línea

Evaluación de un curso en línea para la formación de competencias en el uso de las TIC en profesores de ciencias de secundarias públicas del sureste de México. J. Gabriel Domínguez y J. Samantha Morcillo. 
La categoría Experiencia se dividió en 2 subcategorías que fueron, la primera: proceso complejo con mejoría y la segunda: positiva. La primera, englobó todo el conjunto de conocimientos. vivencias y experiencias por lo cual los profesores no se sintieron cómodos en el desarrollo del programa. Esto incluye elementos como el hecho de que curso haya sido un programa estresante, que en ocasiones fue causa de desesperación y angustia, con poco tiempo para las tareas y en un principio, catalizador de miedo e indecisión en opinión de los interlocutores. Sin embargo, la categoría de proceso complejo con mejoría a pesar de proceder de experiencias "negativas" se enmarca en el denominador común que revaloriza la experiencia y considera que fue provechosa e enriquecedora para su práctica docente.

La segunda englobó todo el conjunto de conocimientos y vivencias por lo cual los profesores se sintieron cómodos en el desarrollo del programa. Esto incluye elementos como: la calidad del curso, la generación de confianza, el aprendizaje de nuevas competencias con información relevante, nivel de dificultad gradual durante el desarrollo del programa, buen clima y que haya sido una experiencia significativa, provechosa y agradable.

Las siguientes son declaraciones de los profesores que sustentan y validan la codificación y categorización de la red conceptual mostrada en la figura anterior acerca del proceso complejo con mejoría.

P7, 15 "me costó trabajo el programa e incluso creo que llegué a fastidiar a mi familia, a mis hijos más que nada porque les preguntaba siempre para que me apoyen y a veces me desesperaba y me angustiaba y mis hijos me llegaron a decir que no nací para la computadora, sin embargo, seguí avanzando en las unidades y fui adquiriendo más confianza."

P8, 16 "en cuanto a la experiencia de trabajar en línea pues lo único que había escuchado del trabajo en línea, era la opinión de algunos compañeros pero ni siquiera tenía una idea de cómo trabajar en este medio, incluso en un principio cuando escuche hablar de las plataformas, me imagine algo muy complicado, incluso sentía miedo de utilizarlas, de echar a perder las cosas, ese miedo que nos transmite la misma gente de la cual nos rodeamos y que no nos ayuda, porque está igual o peor que nosotros."

P4, 12 "también me hubiera gustado que el curso durase más, en ocasiones sentí que el tiempo era mиy poco y que necesitaba más tiempo para poder estudiar y entender los temas, pero espero seguir trabajando y capacitándome en esta área. En general me gustó mucho y espero repetir algún curso de tics con la UADY."

En el análisis de esta categoría es importante contextualizar el proceso de formación que tuvieron los profesores de ciencias, debido que, para muchos de ellos el inicio del proceso formativo fue complicado, difícil y en ocasiones frustrante, fruto de las malas experiencias de programas formativos en los que habían participado previamente y donde declaran que no contaron con el apoyo y el acompañamiento de un tutor en línea que les asesorará con respecto a sus dudas en el programa. Muchos de ellos manifestaron que las dependencias a las cuales pertenecen, solo se preocupan por los recursos de capacitación, sin importar en muchas ocasiones el contexto, el nivel en el que éste se imparte, la habilitación pedagógica del expositor y los estándares mínimos requeridos para poder participar.

Evaluación de un curso en línea para la formación de competencias en el uso de las TIC en profesores de ciencias de secundarias públicas del sureste de México. J. Gabriel Domínguez y J. Samantha Morcillo. 
A continuación, se presentan las declaraciones de los profesores que sustentan la codificación y categorización de la red conceptual mostrada en la figura anterior acerca de las Experiencia Positivas. De igual forma, en contraposición a la categoría de 'proceso complejo, con mejoría' la descripción de las experiencias positivas del programa formativo dan cuenta de que hubieron profesores que debido a las actitudes, experiencias positivas y buen nivel del uso de las tic, incrementaron sus competencias a través de la generación de confianza para consolidar los conocimientos ya adquiridos, el desarrollo de experiencias provechosas y significativas que permearon en su práctica educativa y por el tipo de atención recibida por parte de los tutores en línea, que siempre los acompañaron durante todo el proceso formativo animándose e incentivándolos al cumplimiento s de las actividades de aprendizaje declaradas en el programa.

P20, 5 "bueno realmente para mí fue una experiencia muy significativa porque yo anteriormente nunca había estado en un curso en línea, nunca había estado bajo esas circunstancias y sinceramente si me pareció muy rico en muchos aspectos que me pueden servir en mi trabajo, enfrente mis miedos y gané mucha confianza."

P8, 16 "en realidad en lo personal para mí el curso fue de suma importancia porque yo carecía mucho de las competencias en esta rama, me pareció excelente con un apoyo extraordinario y de gran relevancia en lo particular. Nosotros en la SEP necesitamos más cursos de estos donde aprendamos, no donde nos den contenidos de relleno y no aprendemos nada nuevo."

En la figura 7 se presenta la categoría Expectativas, con las respectivas subcategorías que la integraron extraídas con el procedimiento de Codificación Abierta.

En la figura se puede observar que la categoría Evaluación del curso sintetiza el proceso de Expectativas que tuvieron los interlocutores en el programa formativo. La categoría Expectativas se dividió en 3 subcategorías que fueron no se cumplieron, se cumplieron y se superaron. La primera, englobó las razones por las cuáles los interlocutores consideraron que sus expectativas no se cumplieron. La segunda, englobó las razones que en opinión de los interlocutores fue suficiente para cumplir son sus expectativas. La tercera, consideró las razones por las cuales las expectativas de los interlocutores se vieron superadas durante la implementación del programa formativo. Como se observa en la figura de abajo, las expectativas de los participantes se asocian íntimamente a la satisfacción del usuario. Como menciona Arjona, y Cebrián de la Serna (2011) si la expectativa se realiza habrá satisfacción, si no se realiza habrá frustración. En este sentido se puede ver que la satisfacción en un curso en línea, está predispuesto por la diferencia entre lo que se espera que ocurra (expectativa) y lo que el participante con base a sus experiencias en el curso dice o siente que ocurrió.

El análisis de las expectativas es de gran relevancia en el contexto educativo, debido al reciente crecimiento de la incorporación de las modalidades no convencionales en el ambiente escolar, enfatizando como una de sus fortalezas principales las posibles soluciones que esta modalidad pueda aportar. Lo anterior, vinculado con el actual escenario de austeridad que se vislumbra para todos los niveles educativos, fincan las esperanzas en que el uso de la tecnología pueda verse como una alternativa viable para los acuciantes problemas relacionados con la habilitación tecnológica y la incorporación de los principales actores educativos a la sociedad del conocimiento.

Evaluación de un curso en línea para la formación de competencias en el uso de las TIC en profesores de ciencias de secundarias públicas del sureste de México. J. Gabriel Domínguez y J. Samantha Morcillo. 


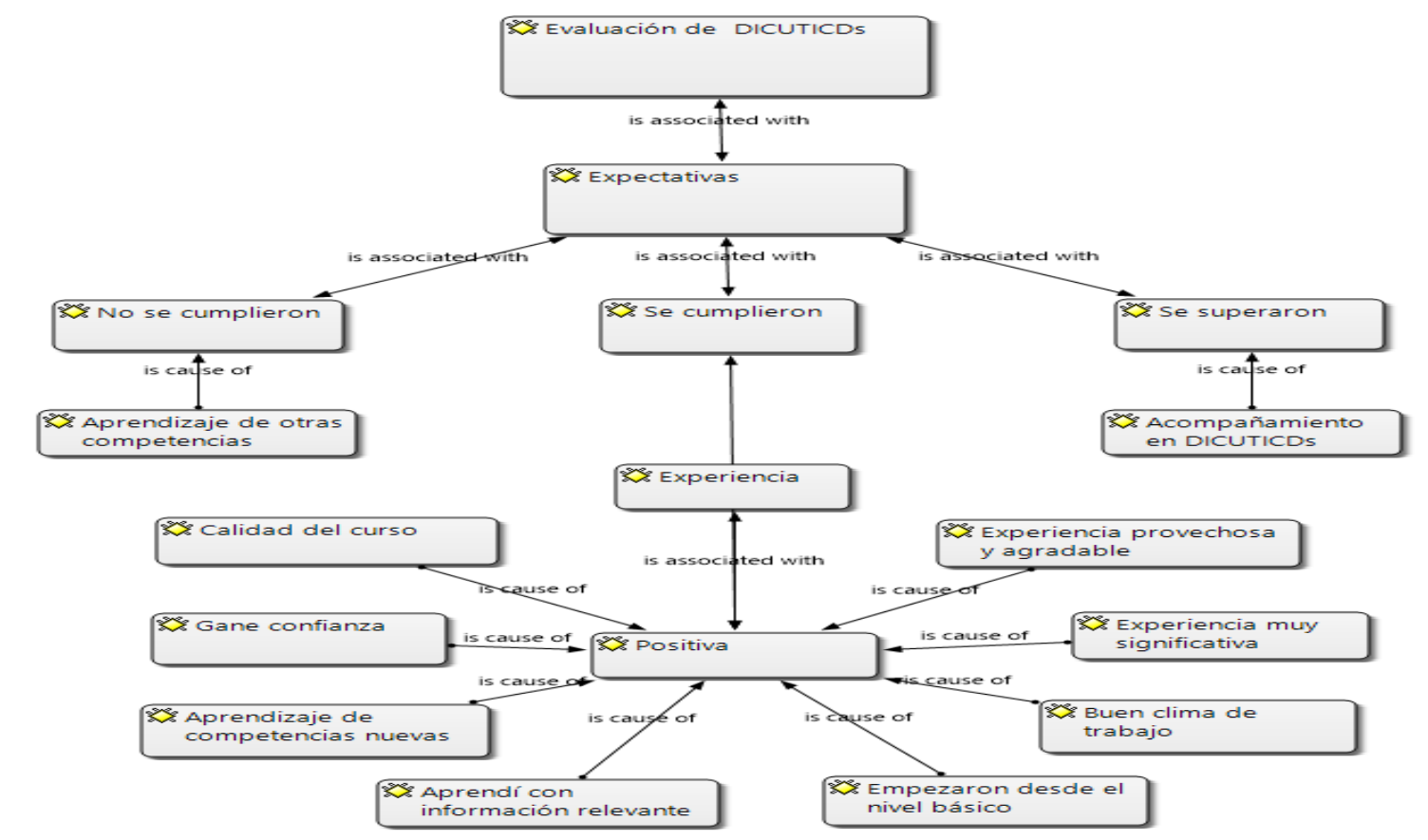

Figura 7. Red conceptual de expectativas

Las siguientes son declaraciones de los profesores que sustentan la codificación y categorización de la red conceptual mostrada en la figura anterior acerca de las Expectativas que no se cumplieron.

P13, 20 "conmigo no, conmigo la verdad no, yo quería aprender otras cosas, pero sin embargo entiendo que fue un curso básico para los maestros."

Las siguientes son declaraciones de los profesores que sustentan la codificación y categorización de la red conceptual mostrada en la figura anterior acerca de las Expectativas que se cumplieron. En este caso la figura anterior muestra, que las expectativas que se cumplieron estuvieron asociadas a una experiencia positiva.

P6, 14 "pues sí, muy completa porque comenzamos de lo más elemental hasta lo más amplio que en realidad fue lo que más me gustó. Ese proceso cubrió mucho de mis expectativas. Además, era muy organizado y de fácil acceso, tanto en los libros electrónicos, presentaciones, videos."

P12, 2 "lo que hizo diferente DICUTICDs, fue el acompañamiento, había tenido muy buenas experiencias antes, pero cero acompañamiento en mis experiencias anteriores, entonces el esfuerzo para nosotros era el triple, y cuando trabajas, tienes doble turno o trabajas en varias escuelas eso mermaba mis resultados."

Sin embargo, de acuerdo con Coll (2011) en la literatura especializada también se encuentran algunos estudios (Benavides y Pedró, 2008; Kozma, 2003, 2005; Ramboll Management, 2006) acerca de la incorporación de las tic que muestran con claridad que en general las expectativas y los discursos acerca del gran impacto de las tic, están sensiblemente alejados de lo que ocurre en las aulas, se indican que hay enormes diferencias entre los países en lo que concierne a la incorporación de las tic a la educación, a la conexión a internet y a la infraestructura mínima requerida.

$\overline{\text { Evaluación de un curso en línea para la formación de competencias en el uso de las TIC en profesores de }}$ ciencias de secundarias públicas del sureste de México. J. Gabriel Domínguez y J. Samantha Morcillo. 
En la figura 8 se puede observar que la categoría Evaluación del curso sintetiza el proceso de las Herramientas de trabajo que tuvieron disponibles los interlocutores para el desarrollo de competencias en el programa formativo. La categoría Herramientas de trabajo se dividió en 7 subcategorías que fueron foros de discusión, presentaciones en power point, lecturas sugeridas, exámenes prácticos, plataforma moodle, enlaces electrónicos, videos y tutoriales y exámenes teóricos. Todas estas herramientas permitieron diferentes tipos de interacción entre los interlocutores que participaron en la acción formativa.

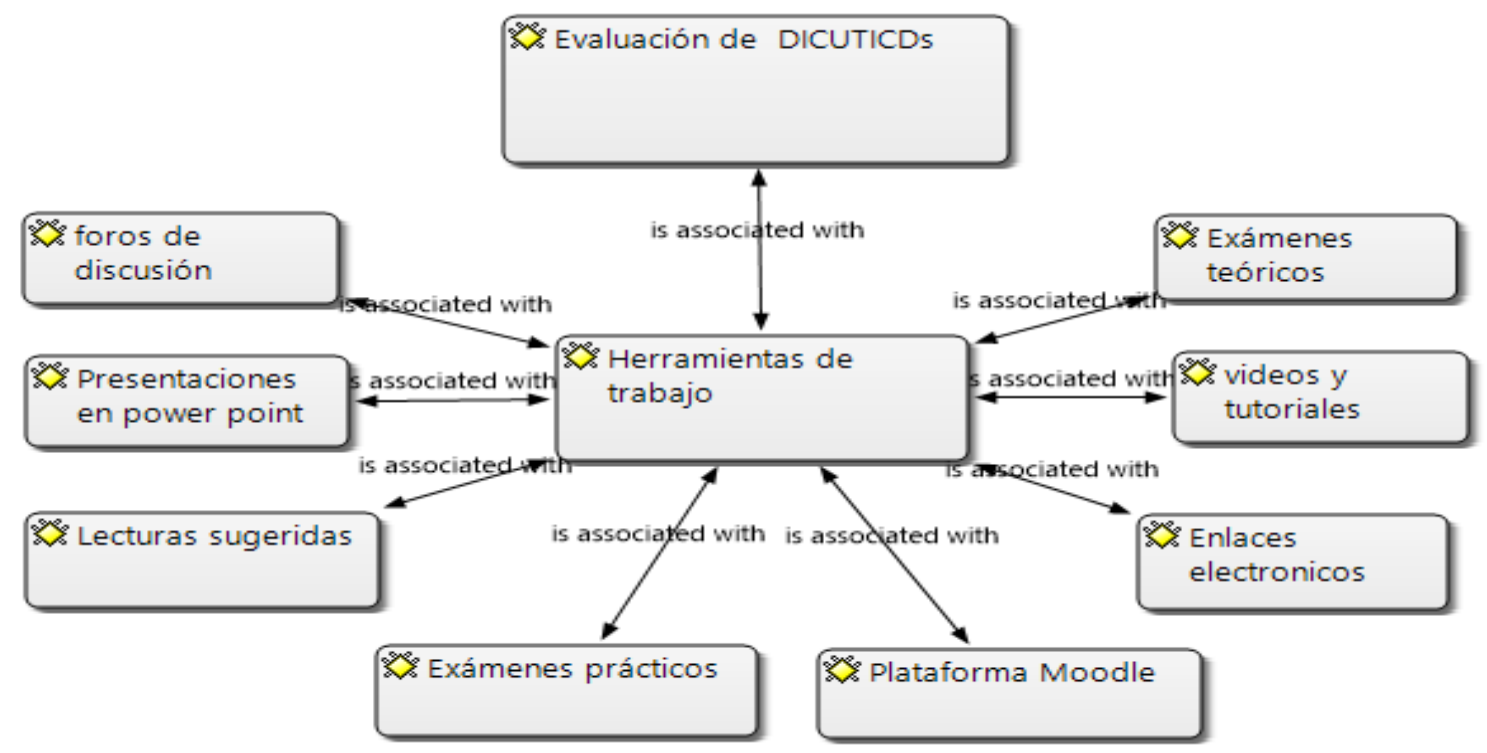

Figura 8. Red conceptual de las herramientas de trabajo

Las siguientes son declaraciones de los profesores que sustentan la codificación y categorización de la red conceptual mostrada en la figura anterior acerca de las Herramientas de trabajo. Este aspecto, fue de gran relevancia en el estudio, ya que en esta modalidad y en opinión de los interlocutores parte del éxito del programa formativo depende de la calidad de éstos, detallando que existieron recursos que partieron de conocimientos declarativos, hasta la oportunidad de reflexionar creativamente.

P19, 4 "pues de lo que me gusto más fue esta parte que es el de la web 2.0, por el hecho de conocer nuevas herramientas, programas e innovaciones. Igual el hecho de trabajar en la plataforma me gustó, los exámenes, foros de discusión. etc. pero te repito me hubiese gustado que nos den un poco más de tiempo para esto."

P7, 15 "en realidad hubo muchos, vimos muchas herramientas fantásticas, la misma plataforma fue muy buena, muy sencilla y bien estructurada, hasta para mí que yo no utilizaba el medio, pero a partir de que empecé a utilizar el curso y fui entendiendo más las unidades, empecé a llevar la computadora a mi salón y la instalaba y conectaba el usb de los chamacos y les mostraba las tareas, como quien dice, clase para ellos, pues la verdad fue muy satisfactoria para mi'”.

P15, 22 "en primer lugar la plataforma nos brindó muchísimas herramientas para ayudarnos al logro de las competencias: materiales, tutoriales, videos, ligas de internet, imágenes, explicaciones claras, un ambiente agradable, además utilizó bonitos colores, otras plataformas son muy feas y secas, no son muy alegres son grises."

Evaluación de un curso en línea para la formación de competencias en el uso de las TIC en profesores de ciencias de secundarias públicas del sureste de México. J. Gabriel Domínguez y J. Samantha Morcillo. 
En la figura 9 se puede observar que la categoría Evaluación del curso sintetizó el proceso de Competencias relevantes, que en opinión de los interlocutores fueron las más significativas y se integraron extraídas con el procedimiento de Codificación Abierta

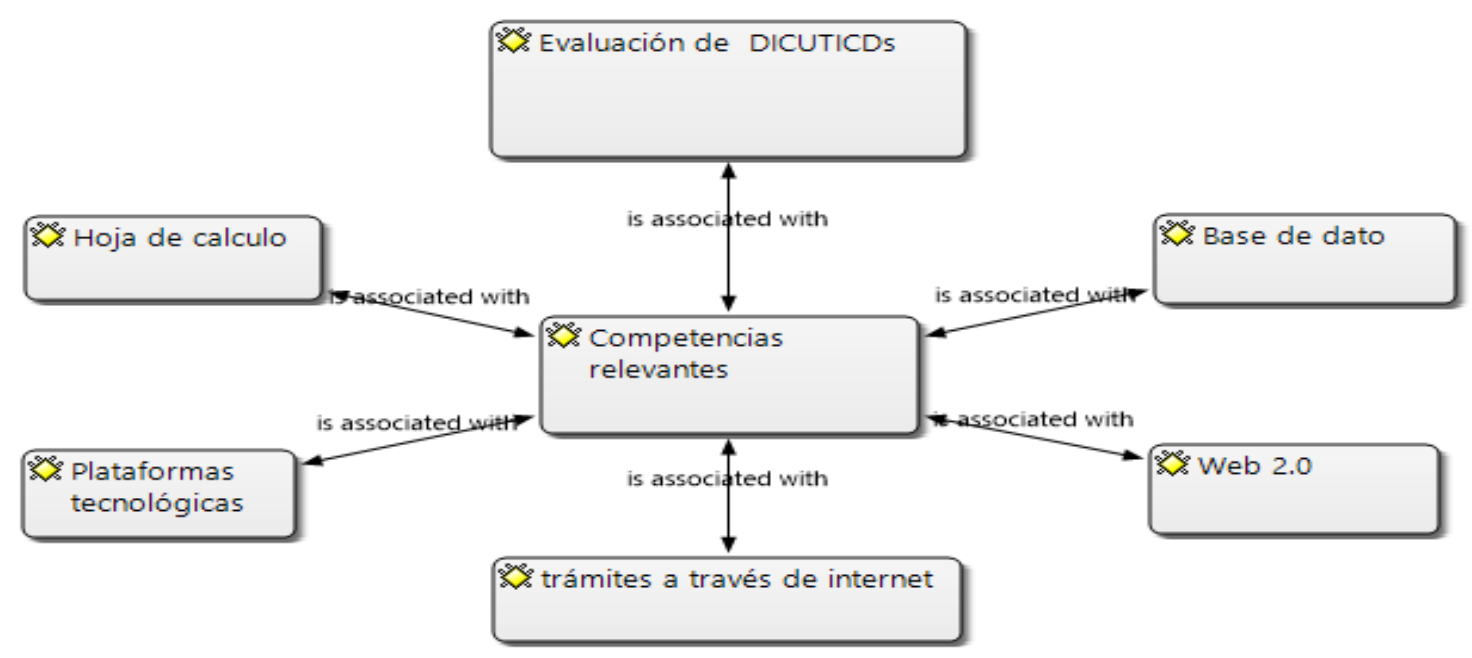

Figura 9. Red conceptual de las competencias relevantes

Las siguientes son declaraciones de los profesores que sustentan la codificación y categorización de la red conceptual mostrada en la figura anterior acerca de las Competencias relevantes, entendidas como las cualidades que necesita desarrollar un profesor a este nivel, que les permita empoderar a sus estudiantes con las ventajas que les aportan el uso de las tic, al mismo tiempo que les permita analizar su práctica educativa y reflexionar acerca de la necesidad de estar habilitados para ofrecer a sus estudiantes oportunidades de aprendizaje apoyados en tic, para utilizarlas y para saber cómo éstas pueden contribuir al aprendizaje de los estudiantes.

P20, 5 "de todas las competencias que vimos las que siento que todavía no domino, aunque admito un gran avance en ellas son las herramientas de la web 2.0, hoja de cálculo y base de datos. Estas fueron muy interesantes, pero siento que todavía necesito practicar más y mejorar."

P19, 4 "la verdad en bases de datos, herramientas de la web 2.0 y plataformas, porque considero que es donde más me interesé, se vieron temas muy interesantes, pero necesito más. Investigaré por mi cuenta, pero si nos pueden apoyar en esos temas sería mejor."

P14, 21 "pues sería por ejemplo la comunicación interpersonal y trabajo participativo en redes, el procesador de textos, el empleo de la hoja de cálculo no tanto para impartir las clases sino para presentar los resultados e informes a la parte administrativa en nuestros trabajos. También los trámites a través de la internet fueron muy interesante y aplicativo y las herramientas de la web".

\section{Conclusión}

$\overline{\text { Evaluación de un curso en línea para la formación de competencias en el uso de las TIC en profesores de }}$ ciencias de secundarias públicas del sureste de México. J. Gabriel Domínguez y J. Samantha Morcillo. 
La literatura especializada en el área de educación (UNESCO, 2008; Zabalza, 2007; Imbernón, 2006; Perrenoud, 2004), ha identificado el dominio de las tecnologías de la información y comunicación, como una de las competencias que deben poseer los docentes para mejorar el desempeño de su profesión y la calidad del aprendizaje. Esta concepción de competencia es atribuible a los docentes desde el nivel básico hasta el nivel superior. En esta investigación se evaluaron las características del curso en línea, para el desarrollo de competencias en el uso de las tic, en profesores de ciencias y matemáticas de secundarias públicas del sureste de México.

Con base al análisis de los resultados podemos concluir que los tres procedimientos fueron bien evaluados por los profesores. Sin embargo, el dominio de navegación y diseño fue el proceso que los profesores calificaron con un mejor funcionamiento, seguido del entorno metodológico y didáctico y por último los recursos multimedia.

De igual forma al analizar el comportamiento de los tres dominios implementados para la evaluación del curso en línea se encontró que el primer (Entorno y Metodología Didáctica) y el tercer dominio (Recursos multimedia) presentaron comportamientos similares entre los grupos de edad pertenecientes a 32 a 41, 42 a 51, y 52 a 61, esto es atribuible a que los tres grupos de edad evaluaron de una manera positiva el funcionamiento de estos procesos en el curso. Un dato atípico, fueron las diferencias encontradas en el segundo dominio (navegación y diseño) sobre todo en profesores pertenecientes al grupo de edad de 52 a 61 años. En el marco de las conclusiones, es importante recalcar que en este estudio los profesores que participaron fueron voluntarios, lo cual deja abierta la posibilidad de encontrar resultados diferentes con otros métodos de selección y con otras poblaciones.

Otra consideración de este estudio, fue la aportación del instrumento diseñado para la valoración de la evaluación de un curso en línea. En conclusión, el instrumento de medición utilizado, proporcionó evidencia cuantitativa y cualitativa que sirvió para la robustecer la calidad de los indicadores técnicos. Desde el punto de vista, de la validez interna, los reactivos mostraron un buen nivel de consistencia interna alineada a cada dominio, y desde el punto de vista de la validez externa, el grupo de expertos (5 jueces) en el área de tecnología educativa valoró la claridad, la importancia, y la relevancia de los ítems utilizados en el instrumento.

Adicionalmente, la evaluación cualitativa del curso en línea proporcionó evidencia acerca de cuáles son las áreas que deben considerarse al momento de la implementación de modalidades no convencionales como esta. Esta consideración fue posible, debido al tipo de enfoque utilizado en esta investigación, que permitió que los participantes emitieran juicios de valor, acerca de la importancia y relevancia de estos procesos. A continuación, se presentan algunas de las categorías que se recomienda se tomen en consideración al momento de elaborar la evaluación de los cursos en línea, ya que de acuerdo con los interlocutores son variables que influyen en el éxito de un curso en esta modalidad. Las variables son: La experiencia previa (conocimientos previos), las expectativas hacia el curso, las actitudes de los profesores, el acompañamiento y asesoría del tutor, las herramientas de trabajo incluidas en el curso, y las competencias relevantes que se desarrollarán.

Evaluación de un curso en línea para la formación de competencias en el uso de las TIC en profesores de ciencias de secundarias públicas del sureste de México. J. Gabriel Domínguez y J. Samantha Morcillo. 
Las implicaciones de los resultados de este estudio se analizan en el contexto de la Estrategia Digital Nacional (2013) emitida por el Gobierno de la República de México que busca como parte de sus líneas de acción:

- Dotar de infraestructura TIC a todas las escuelas del sistema educativo

- Ampliar las habilidades digitales entre los alumnos mediante prácticas pedagógicas (basadas en tic)

- Crear contenidos digitales alineados con los planes curriculares e impulsar la evaluación de estos planes con el objetivo de incorporar el uso de las tic

- Incorporar las tic en la formación docente como herramienta de uso y enseñanza

Este estudio inicia el diálogo acerca de la importancia de la evaluación de los cursos en línea para la formación de profesores en el uso de la tecnología, considerándolo como un elemento clave para la incorporación de las tic en el ámbito educativo y para el fomento de la incorporación de modalidades no convencionales y no pretende extinguir el escepticismo científico que debe imperar en la evaluación de la calidad de la educación y en la evaluación de la calidad de los aprendizajes.

Particularmente, es necesario que las instancias (nacionales, regionales o locales) que diseñan, elaboran y gestionan cursos relacionados con el desarrollo de competencias tecnológicas, convaliden los resultados publicados de este estudio mediante el desarrollo de investigaciones similares con datos colectados de sus respectivos programas formativos. Estos estudios no solo contribuirán a mejorar el desarrollo de competencias en el uso de las tic de los profesores de educación básica, sino también pondrán en marcha el proceso de desarrollar una política nacional de adopción, uso e incorporación de las tic en el proceso de enseñanza-aprendizaje del Sistema Educativo Nacional, basado en datos que demanda México enmarcados en el Plan Nacional de Desarrollo y en los desafíos del contexto digital que declara la Estrategia Digital Nacional.

Presentación del manuscrito: 30 de Diciembre de 2015

Fecha de aprobación: $\quad 15$ de Octubre de 2016

Fecha de publicación: 15 de Noviembre de 2016

Domínguez, G. \& Morcillo, S. (2016). Evaluación de un curso en línea para la formación de competencias en el uso de las Tic en profesores de ciencias de secundarias públicas. RED. Revista de Educación a Distancia. 51(x). Fecha de Publicación. Consultado el (dd/mm/aa) en http://www.um.es/ead/red/XX

\section{Bibliografía}

Alonso, A. (2010). Evaluación de la satisfacción del alumnado de cursos virtuales en la Empresa de Telecomunicaciones de Cuba, S.A (ETECSA). [Artículo en línea]. EDUTEC. Revista Electrónica de Tecnología Educativa, 32. http://edutec.rediris.es/revelec2/revelec32/

$\overline{\text { Evaluación de un curso en línea para la formación de competencias en el uso de las TIC en profesores de }}$ ciencias de secundarias públicas del sureste de México. J. Gabriel Domínguez y J. Samantha Morcillo. 
Arjona, J. y Cebrián de la Serna (2011). Expectativas y satisfacción de usuarios en cursos on line. Estudio del caso: Experto en Entornos Virtuales de Formación. PixelBit. Revista de Medios y Educación, 41, 93-107.

Ashby, J., Sadera, W., y McNary, S. (2011) Comparing student succes between developmental math courses offered online, blended, and face-to-face. Journal of Interactive Online Learning, 10(3).

Bebawi, Sabri G. (2005). Retention and Attrition in Online Classes: Challenges and Potentials. Capella University. Recuperado de: http://gradworks.umi.com/31/79/3179065.html

Benavides, F. y Pedró, F. (2007). Políticas educativas sobre nuevas tecnologías en los países iberoamericanos. Revista Iberoamericana de Educación, 45, 19-69.

Berman, D. (2012). In the Future, Who Will Need Teachers? The Wall Street Journal, 23/10/2012. Recuperado de: http://online.wsj.com/article/SB1000142405297020340060457807508064081 0820.html.

Boggino, N. y Rosekrans, K. (2007). Investigación-acción: reflexión crítica sobre la práctica docente. Edit. Homo Sapiens. España

Bosco, M.; \& Barrón, H. (2008). La educación a distancia en México: Narrativa de una historia silenciosa. México: Universidad Nacional Autónoma de México.

Boxall, M. (2012). MOOC: A Massive Opportunity for Higher Education, or Digital Hype? The Guardian Higher Education Net-work, 8/08/2012. Recuperado de: www.theguardian.com/higher educationnetwork/blog/2012/aug/08/mooc-courserahigher-education investment.

Bryant, K. y Bates, A. (2015). Creating a constructivist online instructional enviroment. Techtrends: Linking Research \& Practice to Improve Learning, 59 (2) 17-22.

Cantaluppi, Raúl F. (2005). Rendimiento académico y abandono en la educación superior a distancia. Recuperado de: http://rediu.colegiomilitar.mil.ar/esp/ediciones/0312/ articulos_originales/ReDiU_0312_art1-Rendimiento_Academico_Parte2.pdf, [consulta: julio de 2012].

Colas, P., Rodriguez, M. y Jimenez, R. (2002). Online Learning in Higher Education: a review of research on interactions among teachers and students. En http://www.usal.es/ teoriaeducacion/rev_numero_06_2/n6_02_art_colas_rodriguez_j im enez.htm (Consulta: 12/04/2008).

Coll, C. (2011). Aprender y enseñar con las TIC: expectativas, realidad y potencialidades. En Carneiro, R.; Toscano, J.C.; Díaz, T. Coord. (2011). Los desafíos de las TIC para el cambio educativo. Colección Metas Educativas 2021. OEI y Fundación Santillana.

Evaluación de un curso en línea para la formación de competencias en el uso de las TIC en profesores de ciencias de secundarias públicas del sureste de México. J. Gabriel Domínguez y J. Samantha Morcillo. 
Cormier, D. y Siemens, G. (2010). Through the Open Door: Open Courses as Research, Learning \& Engagement. Educause Review, 45, 31-39. Recuperado de: http://net.educause.edu/ir/library/pdf/ERM1042.pdf

Diaz, L. A., y Entonado, F. B. (2009). Are the functions of teachers in e-learning and face-to-face learning environments really different? Educational Technology \& Society, 12(4), pp. 331-343. Recuperado de: http://proxy1.ncu.edu/login?url=http://search.ebscohost.com/login.aspx?direct=true\& $\mathrm{db}=$ ehh\&AN=44785119\&site=eds-live

Domínguez, G. (2015). Desarrollo de competencias en el uso de las tic en profesores de ciencias de secundaria (Tesis de Doctorado). España: Universidad de Granada

Domínguez, G. Canto, P., Ortega, J., y McCalman, D. (2016). Raising the Technological Competence of Hihg School Science and Mathematics Teachers of México through Delivery of an Online Program. International Journal of Technology, Policy and Management. Recuperado de: http://www.inderscience.com/info/ingeneral/forthcoming.php?jcode=ijtpm

Elliot, J. (2005). El Cambio Educativo desde la Investigación Acción. (4aEd). Madrid: Ediciones Morata.

Gobierno de la República (2013). Estrategia Digital Nacional. Noviembre, México. http://cdn.mexicodigital.gob.mx/EstrategiaDigital.pdf

Heaton-Schrestha, C.,May, S. and Burke, L (2009) Student retention in higher educationn: what eole role for virtual learning envireonments? Journal of Further and Higher Education, 33(1), pp. 83-92

Hernández, E.E., Romero, S.I. y Ramírez, M.S. (2013). Desarrollo de competencias digitales didácticas en un seminario MOOC. En M.Prieto; S.J. Pech y A. Pérez (Eds), Tecnologías y Aprendizaje, Avances en Iberoamérica (pp. 359-364). Cancún, México: Universidad Tecnológica de Cancún.

Jonassen, D. H. (1997). Instructional design models for well-structure and Ill-structure problem. Solving learning outcomes. Educational Technology: Research and Development, 45 (1), 65-95.

Ko, S. y Rossen, S. (2001). Teaching Online. USA: Houghton Mifflin Co.

Kozma, R. B. (2003). Technology and classroom practices: An international study. Journal of Research on Technology in Education, 36(1), 1-14.

Kozma, R. B. (2005). Monitoring and evaluation of ICT for education impact: a review. En D. A. Wagner, Bob Day, Tina James, Robert B. Kozma, Jonathan Miller y Tim Unwin, Monitoring and Evaluation of ICT in Education Projects: A Handbook for Developing Countries, Washington, DC: infoDev/World Bank. http://www.infodev.org/en/Publication.9.html

Evaluación de un curso en línea para la formación de competencias en el uso de las TIC en profesores de ciencias de secundarias públicas del sureste de México. J. Gabriel Domínguez y J. Samantha Morcillo. 
Karsenti, T., y Lira, M. L. (15 de Mayo de 2010). El Impacto de un Curso en Línea Obligatorio en el Perfil Motivacional de Futuros Profesores. RED - Revista de Educación a Distancia, 22.

Kemmis, S. (1988). Action Research in Retrospect and Prospect, pp. 27-39. En S. Kemmis and $\mathrm{R}$. McTaggart (Eds.) The action research reader, 3rd ed. Deakin University Press, Geelong, Victoria.

Khan, Badrul (2005). Managing E-learning Strategies. Design, Delivery, Implementation and Evaluation. Hershey: Information Science Publishing (Idea Group Inc.).

Mayer, R. E. (2000). Diseño educativo para un aprendizaje constructivista. En C. Reigeluth (Ed.), Diseño de la instrucción. Teorías y modelos (pp. 154-171). Madrid: Aula XXI Santillana.

Mayorga, M. y Madrid, D. (2011). Metodología de evaluación de los cursos on line. España. Universidad de Málaga.

Meyer, K. (2003). The Web's Impact on Student Learning. THE Journal (Technological Horizons in Education), 30(10), 14.

Montilva, J., Barrios, J. y Sandia, B. (2002). A Method Engineering Approach to Evaluate Instructional Products. Actas de la XXVIII Conferencia Latinoamericana de Informática - CLEI'2002. Montevideo, Uruguay, Noviembre.

International North American Council for Online Learning (2011). National Standards for Quality Online Courses 2011. Vienna. www.inacol.org

Quesada Castillo, R. (2006). Evaluación del aprendizaje en la educación a distancia "en línea". RED. Revista de Educación a Distancia, M6 (Número especial dedicado a la evaluación en entornos virtuales de aprendizaje). Recuperado de: http://www.um.es/ead/red/M6

Ramboll Management (2006), E-learning Nordic 2006. Impact of ICT in Education. Documento en línea. Recuperado de: http://www.rambollmanagement.com/eng/sites/pubarr/archive/elearningnordic20061.htm

Romero, C., Ventura, S., y Hervás, C. (2005). Estado actual de la aplicación de la minería de datos a los sistemas de enseñanza basados en web. III Taller de Minería de Datos y Aprendizaje, TAMIDA. Thomson.

Salmon, G. (2000). E-Moderating. London: Kogan Page.

Sandia, B., Montilva, J., y Barrios, J. (2005). Cómo evaluar cursos en línea. Educere, 9(31), octubre-diciembre, 523-530.

Evaluación de un curso en línea para la formación de competencias en el uso de las TIC en profesores de ciencias de secundarias públicas del sureste de México. J. Gabriel Domínguez y J. Samantha Morcillo. 
Schank, R., Berman, T. y Macpherson, K. A. (2000). Aprender a través de la práctica. En C. Reigeluth (Ed.). Diseño de la instrucción. Teorías y modelos (pp. 173-192). Madrid: Aula XXI Santillana

Shah, M., Goode, E., West, S., y Clark, H. (2014). Widening Student Participation in Higher Education through Online Enabling Education. Widening Participation and Lifelong Learning, 16(3), 36-57

Susman, G. I. (1983). Action research: a sociotechnical systems perspective. Beyond method: Strategies for social research, 95-113.

Tam, M. (2000). Constructivism, instructional design, and technology: Implications for transforming distance learning. Educational Technology \& Society, 3(2), 50-60.

Uashby, J. Sadera, W, y McNary, S. (2011) Comparing student succes between developmental math courses offered online, blended, and face-to-face. Journal of Interactive Online Learning, 10(3).

UNAM. (s.f.). Sistema Universidad Abierta y Educación a Distancia. Recuperado de: http://suayed.unam.mx/quees.php

UNESCO (2008). Estándares TIC para la formación inicial docente: Una propuesta en el contexto chileno. Centro de Educación y Tecnología del Ministerio de Educación de Chile (ENLACES). Santiago de Chile.

Universidad Virtual de Michigan (2002). Standards for quality online courses. Recuperado de: http://standards.mivu.org/standards/

Zapata, M. (2013). MOOC, una visión crítica. El valor no está en el ejemplar. Recuperado de: http://eprints.rclis.org/18452/

$\overline{\text { Evaluación de un curso en línea para la formación de competencias en el uso de las TIC en profesores de }}$ ciencias de secundarias públicas del sureste de México. J. Gabriel Domínguez y J. Samantha Morcillo. 